\title{
Platelet-activating factor in the rabbit uterus during early pregnancy*
}

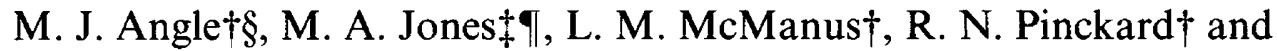 \\ M. J. K. Harper $\ddagger$
}

Departments of $\uparrow$ Pathology and $\ddagger$ Obstetrics and Gynaecology, The University of Texas Health Science Center at San Antonio, San Antonio, Texas 78284, U.S.A.

\begin{abstract}
Summary. Platelet-activating factor (PAF) concentrations were low in the non-pregnant, oestrous uterus (mean \pm s.e.m.: $2 \cdot 2 \pm 1 \cdot 2 \mathrm{pmol} / \mathrm{g}, n=3$ ). However, uterine PAF increased dramatically during pregnancy to a maximum of $37.8 \pm 4.90 \mathrm{pmol} / \mathrm{g}(n=7)$ on Day 5. By Day 7, PAF concentrations in the uteri of pregnant rabbits had returned to levels similar to those found at oestrus. In contrast, uterine PAF in pseudopregnant rabbits peaked at $30.6 \pm 2.8 \mathrm{pmol} / \mathrm{g}(n=8)$ on Day 4 , declined to $20.5 \pm 2.4 \mathrm{pmol} / \mathrm{g}$ $(n=8)$ on Day 5 and then remained at that concentration through Day 7 . Uterine PAF co-migrated with synthetic PAF (1-0-hexadecyl-2-acetyl-sn-glycero-phosphocholine) in both thin-layer and normal-phase high-performance liquid chromatography. PAF activity in the uterus during pregnancy and pseudopregnancy was found almost exclusively in the endometrium; little or no PAF was found in myometrium, uterine flushings or blastocysts. While no PAF was detected in blastocysts on Days 5 and 6 of pregnancy, the presence of the embryo appears to modulate biosynthesis and/or degradation of PAF by the uterus, since PAF decreased significantly in uterine tissue apposed to the implanting embryo (but not in similar areas between such attachment sites). Increased concentrations of PAF in the preimplantation rabbit uterus followed by a dramatic decrease on the day of blastocyst attachment suggest that this potent inflammatory autacoid may play a vital role in implantation.
\end{abstract}

Keywords: PAF; rabbit; uterus; preimplantation events

\section{Introduction}

Increased uterine vascular permeability is one of the earliest indicators of blastocyst implantation (Psychoyos, 1973). Subsequent to changes in vascular permeability, and possibly as a consequence of those changes (Psychoyos, 1973), uterine endometrial stromal cells in many species, including the rabbit, are transformed to glycogen-laden decidual cells. Both increased vascular permeability and the decidual cell response can be elicited by a wide variety of chemical and mechanical stimuli in hormonally primed uteri (DeFeo, 1967; Finn \& Porter, 1975; Lejeune et al., 1981). However, in rabbits, the blastocyst itself provides the most intense stimulus for induction of the decidual cell response (Hoffman et al., 1977).

\footnotetext{
*Reprint requests to Michael J. K. Harper.

§Present address: Cecil H. and Ida Green Center for Reproductive Biology Sciences, The University of Texas Southwestern Medical Center, 5323 Harry Hines Blvd., Dallas, TX 75235, U.S.A.

TPresent address: Department of Chemistry, Felmley Hall 305, Illinois State University, Normal, IL 61761, U.S.A.
} 
The precise mode of communication that signals initiation of implantation is not well characterized. However, several mediators have been implicated as effectors of both vascular permeability and decidualization including histamine, oestrogens and prostaglandins (Shelesnyak, 1957; Saksena et al., 1976; Kennedy, 1977; Jones et al., 1986). Considerable circumstantial evidence has accumulated suggesting that prostaglandins may be essential for the initiation of implantation. Increased concentrations of prostaglandins have been found in endometrial tissue adjacent to the implanting blastocyst (Kennedy \& Zamecnik, 1978), prostaglandins have been found in the preimplantation blastocyst (Dickmann \& Spilman, 1975; Pakrasi \& Dey, 1982; Harper et al., 1983) and pretreatment of pregnant rats with indomethacin abolishes both increased vascular permeability and the decidual response as well as prevents successful implantation (Tobert, 1976; Kennedy, 1979, 1985; Phillips \& Poyser, 1981; Kennedy \& Lukash, 1982). In the rabbit, the role of prostaglandins is not as well defined; treatment of pregnant does with indomethacin reduces the number of implanting blastocysts and delays the onset of implantation and parturition, but does not completely ablate the nidatory process (Hoos \& Hoffman, 1980; Jones et al., 1984). Mediators other than prostaglandins may therefore modulate implantation in the rabbit.

Several members of a family of biologically active phospholipids, collectively known as plateletactivating factors (PAF; 1-0-alkyl-2-acetyl-sn-glycero-3-phosphocholine) have been shown to modulate increased vascular permeability (Wedmore \& Williams, 1981; Humphrey et al., 1982). As little as 1 pmol synthetic PAF initiates post-capillary endothelial cell contraction and increases vascular permeability in the adult rabbit (Humphrey et al., 1982; Humphrey et al., 1984; Angle et al., 1986). Consequently, PAF is one of the most potent vasoactive mediators reported to date. In addition, a substance thought to be PAF is produced by 8 -16-cell mouse embryos in culture (O'Neill, 1985a, b), and administration of a PAF antagonist inhibits implantation in the mouse (Spinks \& O'Neill, 1987) and in the rat (Acker et al., 1987). Therefore, PAF, as well as prostaglandins, may play a critical role in preparing the uterus for implantation of the embryo.

In view of the potent vasoactivity of PAF, experiments to examine its potential role in the onset of events associated with implantation were undertaken by investigating changes in the uterine concentrations of PAF during the early stages of pregnancy and pseudopregnancy in the rabbit.

\section{Materials and Methods}

Animals. Mature New Zealand White-Cambridge female rabbits (body weight $3.0 \mathrm{~kg}$ ) were obtained from Penn Acres Ranch, Wimberley, TX, and caged individually in a controlled environment with a $14 \mathrm{~h}$ light: $10 \mathrm{~h}$ dark cycle, fed $170 \mathrm{~g}$ rabbit pellets/day and provided with tap water ad libitum. Rabbits were injected subcutaneously (s.c.) with 0.5 units pig follicle-stimulating hormone (FSH; Sigma Chemical Co., St Louis, MO) twice a day on Days $-3,-2$, and -1 (Mukherjee et al., 1978). On Day 0, rabbits were inseminated intravaginally with $0.5 \mathrm{ml}$ mixed sperm suspension collected, via an artificial vagina, from fertile bucks immediately before use. After insemination, donor animals were injected intravenously (i.v.) with 100 i.u. human chorionic gonadotrophin (hCG: Ayerst Laboratories, New York, NY). Pseudopregnant animals received the same treatment with FSH and hCG, but were not inseminated. Oestrous animals were selected on the basis of engorgement of the vaginal mucosa (dark red) with blood and received no other treatment. Some animals were subjected to anaesthesia using $30 \mathrm{mg}$ pentobarbitone sodium $/ \mathrm{kg}$ i.v. (Diamond Laboratories, Des Moines, IA) for uterine perfusion before being killed.

Tissue preparation. On various days after insemination, rabbits were killed by i.v. administration of an overdose of pentobarbitone sodium. Uterine horns and ovaries were rapidly removed, blotted, and maintained at $4^{\circ} \mathrm{C}$. Uteri were opened along the line of mesometrial attachment; blastocysts, if present, were removed. Tissue, including blastocysts, ovaries, uteri and segments of bladder were weighed, homogenized (using a Brinkman Polytron at setting 7 for 30 sec) in $5 \mathrm{ml} 10 \%$ neutral buffered formalin $(\mathrm{v} / \mathrm{v})$ and extracted for $1 \mathrm{~h}$ after the addition of $15 \mathrm{ml}$ chloroform:methanol $(1: 2, \mathrm{v} / \mathrm{v})$ using a modification of the procedure of Folch et al. (1957) (see below). $\left[{ }^{3} \mathrm{H}\right] \mathrm{PAF}\left(1-0-\left[{ }^{3} \mathrm{H}\right]\right.$-hexadecyl-2acetyl-sn-glycero-3-phosphocholine, C16:0-AGEPC) obtained by sequential h.p.l.c. fractionation of 1-0-[ $\left.{ }^{3} \mathrm{H}\right]$-alkyl2-acetyl-sn-glycero-phosphocholine (sp. act. 30-60 Ci/mmol; New England Nuclear, Boston, MA) was added to each sample (5500 d.p.m.) for estimation of PAF recovery.

Blastocysts were routinely collected from uterine flushings or the exposed endometrium of the uterus, pooled and, following lipid extraction/fractionation, assayed for PAF activity (see below). In selected experiments, blastocyst 
production of PAF in culture was examined. Blastocysts were recovered by flushing the uteri of rabbits on Day 5 of pregnancy, and those not cultured were washed three times in ice-cold Tyrode's solution $(154 \mathrm{~mm}-\mathrm{NaCl}, 2 \cdot 68 \mathrm{mM}-\mathrm{KCl}$, $0.98 \mathrm{mM}_{-} \mathrm{MgSO}_{4}, 11.90 \mathrm{mM}-\mathrm{NaHCO}_{3}, 1.80 \mathrm{mM}-\mathrm{CaCl}_{2}$, and $5.55 \mathrm{~mm}$-dextrose, pH 7.4), and then pooled. Blastocysts that were to be cultured in vitro were collected as rapidly as possible, pooled, transferred to sterile Petri dishes and incubated in Tyrode's buffer at $37^{\circ} \mathrm{C}$ for $24 \mathrm{~h}$. Blastocysts and culture media were lipid-extracted, fractionated on t.l.c. and assayed for PAF activity.

To determine potential intravascular contributions to uterine PAF concentrations, uteri were also perfused over a 20-30 min period under general anaesthesia via the abdominal aorta with $250 \mathrm{ml}$ Krebs-Ringer-bicarbonate buffer (1 $19 \mathrm{~mm}-\mathrm{NaCl}, 4 \cdot 7 \mathrm{~mm}-\mathrm{KCl}, 1 \cdot 2 \mathrm{mM}-\mathrm{MgSO}_{4}, 25 \mathrm{~mm}-\mathrm{NaHCO}_{3}, 1 \cdot 7 \mathrm{~mm}-\mathrm{CaCl}_{2}$ and $5 \mathrm{~mm}$-dextrose, pH 7.4) containing heparin at a perfusion pressure of $90 \mathrm{mmHg}$ (Hoos \& Hoffman, 1983). While not all perfusion fluid passed through the uterus, at the end of the perfusion procedure the uteri were completely blanched. After perfusion, uteri were removed, weighed and extracted for subsequent t.l.c. and PAF analysis.

Lipid extraction. Preliminary studies were conducted to determine the most effective method for extraction of lipids from tissue and blastocysts. The two procedures utilized were modifications of those described by Folch et al. (1957) and Bligh \& Dyer (1959). For tissue samples, the Folch procedure proved to be superior, resulting in $100 \%$ recovery of $\left[{ }^{3} \mathrm{H}\right]$ PAF compared to only $85 \%$ recovery for the other procedure. Tissue samples up to $1 \mathrm{~g}$ were therefore homogenized in $5 \mathrm{ml}$ neutral buffered formalin (see above) followed by the addition of $15 \mathrm{ml}$ chloroform:methanol $(1: 2, \mathrm{v} / \mathrm{v})$; the mixture was incubated at room temperature for $1 \mathrm{~h}$ followed by centrifugation at $3000 \mathrm{~g}$ for $10 \mathrm{~min}$. The supernatant was removed and sufficient chloroform and water added $(5 \mathrm{ml}$ and $4 \mathrm{ml}$, respectively) to result in a chloroform: methanol:water ratio of 1:1:0:9 (by vol.) to effect phase separation. All PAF was found in the lower chloroform-rich phase. For the lipid extraction of blastocysts suspended in tissue culture medium, one volume of chloroform and two volumes of methanol were added to 0.8 volume of tissue culture medium containing the blastocysts. After 60 min incubation at room temperature followed by centrifugation at $3000 \mathrm{~g}$ for $10 \mathrm{~min}$, the supernatant was removed and one volume each of chloroform and water was added to effect phase separation. The chloroform-rich layers obtained by either procedure were removed and were stored at $-20^{\circ} \mathrm{C}$ until they were further purified by t.l.c. or h.p.l.c. (see below).

Chromatography. Uterine homogenate extractions were subjected to two sequential t.l.c. procedures to enhance separation of uterine platelet-stimulating activity from other co-migrating and inhibitory lipids (Miwa et al., 1987). Samples were evaporated to dryness under a stream of nitrogen at $37^{\circ} \mathrm{C}$, resuspended in chloroform containing $1 \%$ methanol and water, applied to Analtech (Analtech Inc, Newark, DE) precoated Silica Gel G preparative plates $(1000 \mu \mathrm{m})$ and developed in chloroform:methanol:water $(65: 35: 6$, by vol.). The region corresponding to synthetic PAF $\left(R_{\mathrm{f}}=0.21\right)$ was removed and lipid was extracted by the procedure of Bligh \& Dyer (1959). The PAF-containing fractions were then re-chromatographed on Analtech $200 \mu \mathrm{m}$ Silica Gel $G$ plates using the same solvent system. The t.l.c. fractions were removed and lipid-extracted into chloroform which was retained (at $-20^{\circ} \mathrm{C}$ ) for subsequent PAF bioassay. Additional t.l.c. or h.p.l.c. purification did not lead to further increases in PAF activity, indicating adequate separation of the inhibiting lipid(s) from uterine PAF by the two sequential t.l.c. procedures.

Normal-phase h.p.l.c. was performed on uterine extracts following the procedures described by Pinckard et al. (1984). Elution of uterine PAF was monitored by platelet bioassay of each h.p.l.c. fraction.

Platelet bioassay. The platelet-activating activity in t.l.c. or h.p.l.c. fractions was functionally assessed by the release of $5-\left[1,2{ }^{3} \mathrm{H}(\mathrm{N})\right]$ hydroxytryptamine (sp. act. $30 \mathrm{Ci} / \mathrm{mmol}$; New England Nuclear; Boston, MA) from washed rabbit platelets as previously described by Pinckard et al. (1979). Briefly, samples in chloroform were evaporated under nitrogen and resuspended in pyrogen-free saline containing $0.25 \%$ bovine serum albumin (Miles Laboratories Inc., Elkhart, IN). Then $200 \mu \mathrm{l}$ pre-warmed washed rabbit platelets $(250000 / \mu \mathrm{l})$ were added to $4 \mu \mathrm{l}$ of various dilutions of sample. After $60 \mathrm{sec}$, the reaction was terminated by the addition of $20 \mu \mathrm{l} 1.5 \mathrm{M}$-formalin. PAF activity in the samples was assessed by comparing the percentage $\left[{ }^{3} \mathrm{H}\right]$ serotonin released to that induced by synthetic PAF (1-0-hexadecyl-2acetyl-sn-glycero-3-phosphocholine) (Bachem Fine Chemicals, Torrance, CA), assayed in parallel. If a sample failed to effect $\left[{ }^{3} \mathrm{H}\right]$ serotonin release, it was assessed by the more sensitive evaluation of platelet aggregation (Pinckard et al., 1979) in the presence of $10 \mu \mathrm{M}$-indomethacin (Sigma) and creatine kinase/creatine phosphate, $5 \mathrm{u} / \mathrm{ml}, 2 \mathrm{~mm}, \mathrm{respectively}$ (Sigma). In these assays $10 \mu \mathrm{l}$ aliquants of the unknown samples were added to $500 \mu 1$ of washed rabbit platelets $(250000 / \mu \mathrm{l})$ stirred at 900 r.p.m. with a stirring microbar in a platelet aggregometer (Payton, Buffalo, NY). The subsequent platelet aggregation responses were compared to aggregation curves obtained with standard amounts of synthetic PAF assayed in parallel.

The sensitivity for detecting synthetic PAF activity was $11 \mathrm{fmol}$ for the platelet $\left[{ }^{3} \mathrm{H}\right]$ serotonin secretion assay and $6 \mathrm{fmol}$ for platelet aggregation. Since only $4 \mu \mathrm{l}$ and $10 \mu \mathrm{l}$ of the unknown samples (dissolved in a total of $100 \mu \mathrm{l}$ salinealbumin) were utilized in the platelet secretion and platelet aggregation assays respectively, the absolute sensitivities of these two assays for detecting PAF in the unknown samples were therefore 0.27 and 0.06 pmol. The PAF activity in unknown samples was calculated as the equivalent platelet $\left[{ }^{3} \mathrm{H}\right]$ serotonin secreting and/or aggregating activity of the synthetic PAF standard; the reported amounts of PAF were corrected for loss during t.l.c. purification (15-45\%) as estimated by measurement of the $\left[{ }^{3} \mathrm{H}\right] \mathrm{PAF}$ tracer in each t.l.c. fraction. Recovery during extraction was $100 \%$ using the Folch procedure.

Statistical analyses. Differences between means were tested by analysis of variance and Student-Newman-Keuls test (Sokal \& Rohlf, 1969) for groups of unpaired data. Probability values of $P<0.05$ were considered significant. Linear trends were analysed by use of multiple linear regression analysis (Sokal \& Rohlf, 1969). 
Table 1. Time course of in-vitro PAF formation in uterine tissue from pregnant rabbits

\begin{tabular}{|c|c|c|c|}
\hline \multirow{3}{*}{$\begin{array}{l}\text { Day of } \\
\text { pregnancy }\end{array}$} & \multicolumn{3}{|c|}{$\mathrm{PAF}$ concentration $(\mathrm{pmol} / \mathrm{g}$ ) } \\
\hline & \multicolumn{3}{|c|}{ Time after tissue removal (min) } \\
\hline & $0^{*}$ & 5 & 10 \\
\hline Oestrus & $1.9 \pm 1.0^{8} \dagger$ & $1.8 \pm 0.7^{8}$ & $2 \cdot 5 \pm 0.6^{8}$ \\
\hline 1 & $3 \cdot 1 \pm 1 \cdot 0^{\mathrm{g}}$ & $1.8 \pm 0.5^{\mathrm{g}}$ & $2 \cdot 7 \pm 0.5^{\mathrm{g}}$ \\
\hline 2 & $4 \cdot 1 \pm 1 \cdot 0^{8}$ & $7.2 \pm 3.0^{8}$ & $18 \cdot 6 \pm 2 \cdot 0^{f, g}$ \\
\hline 3 & $3 \cdot 2 \pm 1 \cdot 6^{8}$ & $32 \cdot 2 \pm 12 \cdot 9^{d, e, f}$ & $52 \cdot 2 \pm 4 \cdot 1^{a, b}$ \\
\hline 4 & $11 \cdot 3 \pm 4 \cdot 1^{f, g}$ & $44 \cdot 2 \pm 6 \cdot 5^{\mathrm{b} \cdot c, \mathrm{~d}}$ & $64 \cdot 5 \pm 11 \cdot 6^{\mathrm{a}}$ \\
\hline 5 & $14 \cdot 1 \pm 3 \cdot 3^{r, g}$ & $39 \cdot 6 \pm 10 \cdot 9^{\mathrm{b}, \mathrm{c}, \mathrm{d}, \mathrm{e}}$ & $51 \cdot 8 \pm 5 \cdot 0^{\mathrm{a}, \mathrm{b}, \mathrm{c}}$ \\
\hline 6 & $5 \cdot 4 \pm 0.3^{8}$ & $25 \cdot 8 \pm 3 \cdot 7^{\mathrm{d}, e, f, g}$ & $22 \cdot 9 \pm 2 \cdot 3^{e . f . g}$ \\
\hline 7 & $5 \cdot 0 \pm 2 \cdot 3^{\mathrm{g}}$ & $6 \cdot 1 \pm 2 \cdot 4^{\mathrm{g}}$ & $11 \cdot 3 \pm 0 \cdot 6^{\mathrm{f}, \mathrm{g}}$ \\
\hline
\end{tabular}

*Zero time equals the fastest the tissue could be processed from the time of death $(\sim 1 \mathrm{~min})$.

$\dagger$ Data are expressed as the mean ( \pm s.e.m.) values for uteri from 3 rabbits. Values with different letter superscripts differ significantly $(P<0 \cdot 05)$.

\section{Results}

\section{Tissue extraction procedures}

In initial studies, the effect of elapsed time during the manipulations required to remove, mince and homogenize the tissue upon subsequent PAF recovery was examined. Uteri were removed from does on sequential days of gestation, minced and allowed to remain on ice. At various times, $250 \mathrm{mg}$ samples of minced tissue were homogenized, extracted and ultimately assayed for PAF activity (Table 1). Physical manipulation of ovarian or bladder tissue and uteri from oestrous does (data not shown) or from animals on Days 1,2,6 and 7 of pregnancy did not result in significantly increased amounts of PAF formed with time. In contrast, removing and mincing uteri on Days 3 through 5 of pregnancy significantly enhanced the levels of PAF generated throughout the 10-min experimental period. The greatest amount of PAF was synthesized by uteri from these days at both the 5- and 10 -min time points. This in-vitro production of PAF by the pregnant uterus was decreased by Day 7 . These observations suggest that cells of the pregnant uterus can be mechanically activated and respond by synthesizing PAF. In all experiments described below, therefore, mincing and lipid extraction were performed rapidly (i.e. in less than $2 \mathrm{~min}$ ) to minimize post-mortem production of PAF.

\section{Chromatographic similarity between uterine $P A F$ activity and synthetic $P A F$}

After repetitive t.1.c., the $R_{\mathrm{f}}$ value $(0 \cdot 21)$ of uterine PAF was identical to that for synthetic PAF (C16:0-AGEPC). Not only did platelet-activating activity from uterine tissue co-migrate on t.l.c. with synthetic PAF but the activity co-eluted with C16:0-AGEPC after normal-phase h.p.l.c. fractionation (Fig. 1). These observations would suggest that uterine PAF structurally resembles synthetic PAF.

\section{$P A F$ activity in uteri from pregnant does}

Modified Folch extraction, repeated t.l.c. and platelet secretion and aggregation assays were used to determine whether PAF activity was present in uteri from oestrous, pseudopregnant and pregnant rabbits and to examine temporal changes in uterine PAF concentrations during the preimplantation 


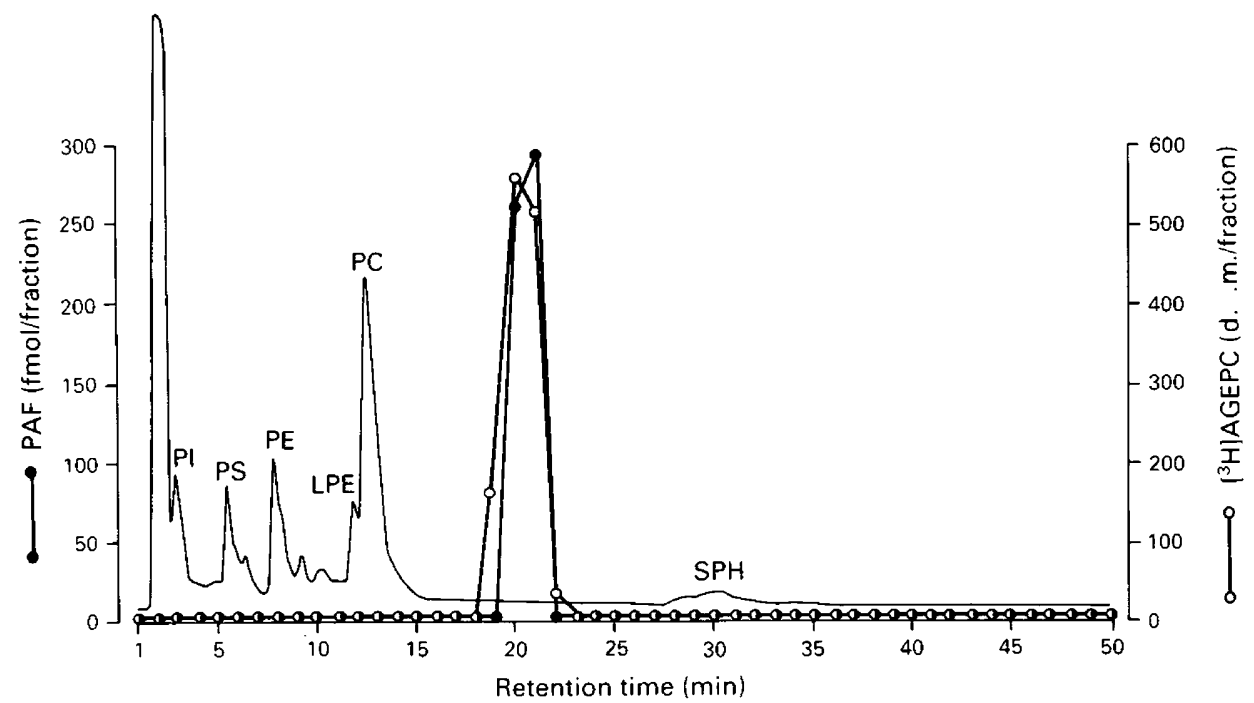

Fig. 1. Elution profiles of uterine PAF (solid circles) and $\left[{ }^{3} \mathrm{H}\right] \mathrm{C} 16: 0-A G E P C$ tracer (open circles) from normal-phase h.p.l.c. The unbroken, solid line is the u.v. absorption profile of uterine lipids in the sample: PI, phosphatidylinositol; PS, phosphatidylserine; PE, phosphatidylethanolamine; LPE, lysophosphatidylethanolamine; PC, phosphatidylcholine; SPH, sphingomyelin. This normal-phase h.p.l.c. chromatogram is representative of 4 separate experiments.

period (Fig. 2). PAF activity was found in uteri from oestrous rabbits, albeit in very low concentrations (mean \pm s.e.m.: $2 \cdot 2 \pm 1 \cdot 2 \mathrm{pmol} / \mathrm{g}$ wet weight tissue, $n=3$ ). PAF was also found in segments of bladder in concentrations that neither differed significantly from those found in the oestrous uterus nor changed throughout early pregnancy or pseudopregnancy. Consequently, all values were pooled to give a mean value of $5 \cdot 1 \pm 0.6 \mathrm{pmol} / \mathrm{g}(n=13)$.

PAF was also found in ovarian tissue (Fig. 2). Ovarian PAF remained low and unchanged for the first 7 days of pregnancy, and so the values were pooled to give a mean value of $2.8 \pm 0.4 \mathrm{pmol} / \mathrm{g}(n=13)$; this value did not differ from that for the uterus of oestrous animals.

In contrast, PAF levels in the uterus rose dramatically during pregnancy or pseudopregnancy (Fig. 2); however, the temporal pattern of PAF formation during the nidatory period differed significantly in uteri from pregnant as compared to pseudopregnant rabbits. During pregnancy, PAF activity was low in uteri removed from rabbits on the first day of pregnancy, but increased significantly to reach a peak between Days $4(34 \cdot 8 \pm 6 \cdot 6 \mathrm{pmol} / \mathrm{g}, n=8)$ and $5(37 \cdot 8 \pm 4 \cdot 9, n=7)$ and then dropped slightly, but not significantly on Day 6. However, by Day 7 of pregnancy, PAF activity in the uterus had returned to levels $(4 \cdot 9 \pm 0 \cdot 7 \mathrm{pmol} / \mathrm{g}, n=6)$ that were not significantly different from PAF concentrations in the oestrous uterus. These measurements were made on random $1 \mathrm{~g}$ samples taken from whole uteri, and the actual values recorded may reflect a greater contribution of implantation sites (see Table 3).

In uteri from pseudopregnant rabbits (Fig. 2), the temporal development of PAF activity on Days 1 through 4 was similar to that seen in pregnancy; PAF activity was low in uteri on Day 1, rose on Days 2 and 3 and peaked on Day 4 at $30.5 \pm 2.8 \mathrm{pmol} / \mathrm{g}(n=7)$. However, in contrast to the activity in uteri from pregnant animals, which remained high through Day 6 and then declined at the time of implantation, activity in uteri from pseudopregnant does dropped significantly to $20 \cdot 5 \pm 2 \cdot 4 \mathrm{pmol} / \mathrm{g}(n=8)$ on Day 5 and remained at that level on Days 6 and 7 . 


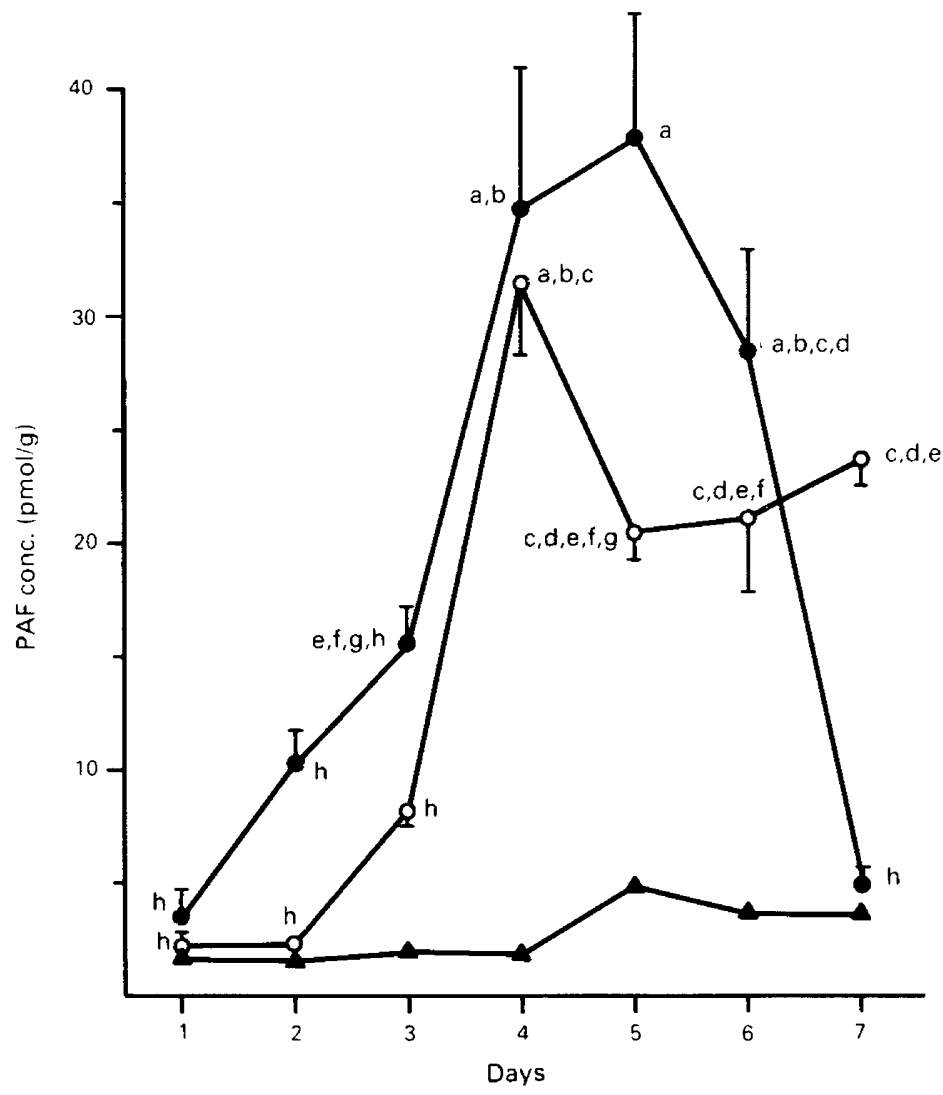

Fig. 2. PAF activity in uterine ( $)$ and ovarian ( $\mathbf{A}$ ) tissues from pregnant rabbits and in uterine tissues $(O)$ from pseudopregnant rabbits. Each point represents the mean \pm s.e.m. for data derived from 68 animals during pregnancy or pseudopregnancy; ovarian PAF data represent the means for 2 animals on each day of pregnancy. Values with different letter superscripts differ significantly $(P<0 \cdot 05)$.

When these data were analysed by linear regression analysis for correlations with days of pregnancy or pseudopregnancy, there were significant linear increases of PAF concentration in pregnant and pseudopregnant animals during Days 1-4 (Table 2). These regressions did not differ significantly. In pregnant animals on Days 5-7 there was a significant regression with a negative slope, while in pseudopregnant animals during the same period there was no significant trend and the slopes of the lines differed significantly. Furthermore, analysis of the data from the pregnant animals showed that an even better linear trend was observed when the data from the Day-5 animals were also included (Table 2).

\section{Potential sources of uterine PAF}

Possible sites of origin for the PAF in uteri were investigated. No detectable PAF activity was found in extractions of three pools of 10 blastocysts removed from the uterus on Day 5 and cultured for $24 \mathrm{~h}$ in extracts of the culture medium (data not shown). In addition, no PAF activity was found in flushings from uteri on Days 5 or 6 of pregnancy or in blastocysts removed on Day 5 or on Day 6 and extracted directly without culture. While the rabbit blastocyst may not synthesize and release detectable PAF, there appeared to be a blastocyst-uterine interaction occurring at the time of 
Table 2. Changes in PAF concentrations in rabbit uterus as a function of day of pregnancy or pseudopregnancy

\begin{tabular}{lccccc}
\hline Status & Days & $\begin{array}{c}\text { No. of } \\
\text { observations }\end{array}$ & $\begin{array}{c}\text { Regression equation* } \\
y=\end{array}$ & $\mathrm{S}_{\mathrm{b}}$ & Significance \\
\hline Pregnant & $1-4$ & 30 & $-9 \cdot 31+10 \cdot 03 x^{\mathrm{a}}$ & 1.73 & $P<0.001$ \\
Pseudopregnant & $1-4$ & 29 & $-11 \cdot 52+9 \cdot 89 x^{\mathrm{a}} \mathrm{b}$ & $1 \cdot 26$ & $P<0.001$ \\
Pregnant & $5-7$ & 21 & $121 \cdot 55-16 \cdot 21 x^{\mathrm{c}}$ & 3.08 & $P<0.001$ \\
Pseudopregnant & $5-7$ & 24 & $10 \cdot 58+1.90 x^{\mathrm{b}}$ & $2 \cdot 01$ & $P=0.6$ \\
Pregnant & $1-5$ & 37 & $-8.08+9 \cdot 13 x^{\mathrm{a}}$ & $1 \cdot 29$ & $P<0.001$ \\
\hline
\end{tabular}

${ }^{*} y=$ PAF concentration (pmol per $\mathrm{g}$ wet weight of tissue); $x=$ days.

Differences between regressions were tested by multiple regression analysis (Sokal \& Rohlf, 1969).

Regressions with different letter superscripts differ significantly $(P<0.05)$.

Table 3. PAF activity in blastocysts and uterine implantation or inter-implantation regions

\begin{tabular}{lcc}
\hline Source of PAF & $\begin{array}{c}\text { No. } \\
\text { of rabbits* }\end{array}$ & $\begin{array}{c}\text { PAF activity } \\
\text { (pmol/g tissue) }\end{array}$ \\
\hline Day 6 & 5 & None detectable \\
$\quad$ Blastocysts & 3 & $26 \cdot 3 \pm 3 \cdot 8^{\mathrm{a}}$ \\
Implantation sites & 3 & $22 \cdot 7 \pm 1 \cdot 8^{\mathrm{a}}$ \\
Inter-implantation sites & 3 & $5 \cdot 5 \pm 1 \cdot 3 \dagger^{\mathrm{c}}$ \\
$\quad$ Implantation sites & 3 & $14 \cdot 0 \pm 1 \cdot 5^{\mathrm{b}}$ \\
$\quad$ Inter-implantation sites & 3 & \\
\hline
\end{tabular}

* Blastocysts from an individual rabbit were pooled. The total number of pooled blastocysts from each animal ranged between 5 and 20 .

Implantation sites on Day 7 included attached blastocysts.

Values (mean \pm s.e.m.) with different letter superscripts differ significantly $(P<0.05)$.

implantation which affects uterine PAF activity (Table 3). When uteri on Day 6, just before attachment of the blastocyst, were carefully but rapidly $(<2 \mathrm{~min})$ dissected and the uterine tissue underlying the blastocysts (by visual inspection of the blastocysts) was extracted separately from sections of uteri not in contact with the implanting blastocyst, PAF activity in the two areas was not significantly different. However, by Day 7 , the activity at the implantation sites was significantly less than the activity in the inter-implantation areas (Table 3).

A likely source of PAF in the uteri is from the cells of the endometrium itself. Uteri from oestrous, pregnant or pseudopregnant rabbits were removed and the endometrium was gently scraped from the underlying myometrium with a glass slide (all steps were done over ice). After lipid extraction and fractionation, PAF activity was analysed in the endometrial and myometrial fractions (Table 4). Essentially all of the PAF activity in the uterus occurred in the endometrium rather than the myometrium.

Circulating cells including neutrophils, basophils, monocytes and platelets can synthesize PAF. These cells do not store preformed PAF, but synthesize PAF immediately after cellular activation. These intravascular cells therefore present another possible source of uterine PAF, e.g. the physical manipulation and trauma associated with removal of the hyperaemic uterus might initiate intravascular PAF synthesis and release. Therefore, uteri from anaesthetized oestrous or Day 6 pseudopregnant rabbits were perfused with $250 \mathrm{ml}$ Krebs-Ringer buffer via the abdominal aorta; visual 
Table 4. PAF distribution in endometrium and myometrium of oestrous, pseudopregnant and pregnant rabbits

\begin{tabular}{|c|c|c|}
\hline \multirow[b]{2}{*}{ Uterine status } & \multicolumn{2}{|c|}{$\begin{array}{l}\text { PAF concentration } \\
\text { (pmol/g tissue) }\end{array}$} \\
\hline & Endometrium & Myometrium \\
\hline Oestrous & $2 \cdot 2 \pm 1 \cdot 2$ & $0.4 \pm 0.2$ \\
\hline Pseudopregnant (Day 6) & $18 \cdot 2 \pm 5 \cdot 1$ & $2 \cdot 4 \pm 1 \cdot 1^{*}$ \\
\hline Pregnant (Day 6) & $28 \cdot 2 \pm 8 \cdot 3$ & $2 \cdot 0 \pm 1 \cdot 5^{*}$ \\
\hline
\end{tabular}

Values are mean \pm s.e.m. ( 3 animals/group).

${ }^{*} P<0.05$ compared with value for endometrium.

Table 5. The effect of vascular perfusion on PAF activity in endometria from oestrous and Day-6 pseudopregnant rabbits

\begin{tabular}{lcc}
\hline Uterine status & $\begin{array}{c}\text { Vascular } \\
\text { perfusion } \\
\text { before death }\end{array}$ & $\begin{array}{c}\text { PAF conc. } \\
\text { (pmol/g } \\
\text { tissue) }\end{array}$ \\
\hline Oestrous & + & $3 \cdot 0 \pm 1 \cdot 2$ \\
Oestrous & - & $2 \cdot 2 \pm 1 \cdot 2$ \\
Pseudopregnant & + & $19 \cdot 5 \pm 4 \cdot 2$ \\
Pseudopregnant & - & $18 \cdot 2 \pm 5 \cdot 1$ \\
\hline
\end{tabular}

Values are mean \pm s.e.m. ( 3 animals/group).

inspection of the uterine effluent indicated the absence of erythrocytes. The endometrium was removed by scraping, the lipids extracted, and, after t.l.c. fractionation, PAF activity was determined (Table 5). Perfusion of the uterus did not affect PAF activity in endometria from oestrous or pseudopregnant animals.

\section{Discussion}

Successful implantation of the blastocyst requires synergistic interactions between the developing embryo and the uterus, culminating in embryonic attachment at a receptive location in the uterus. The mechanism whereby the embryo signals its presence and initiates a complementary series of uterine events is not fully understood but a variety of chemical mediators (i.e. histamine, prostaglandins and oestrogen) have been implicated in the process. Many of these mediators are also involved in the development of an inflammatory response (Majno, 1964). In addition, implantation and inflammation have several physiological events in common, including development of tissue oedema, increased vascular permeability and secondary mediator release (including prostaglandins, thromboxanes and leukotrienes). Since synthetic platelet-activating factor (PAF) initiates many of the events associated with inflammation (McManus, 1986), the potential involvement of PAF in implantation was examined. The results of this study extend our earlier preliminary report (Angle et al., 1985) and document that PAF concentrations increase significantly in the uterus during the preimplantation period when peripheral progesterone concentrations are increasing. In contrast, bladder and ovarian PAF values do not change during the same time period. Furthermore, temporal 
production of PAF in the uterus is influenced by the presence of the preimplantation embryo, as shown by the dramatic decline by Day 7 in pregnant animals. These findings therefore suggest that uterine PAF plays an important role in early events leading to successful implantation of the embryo.

PAF has also been found in the non-pregnant rat uterus, a total PAF content of $21 \cdot 3 \mathrm{ng} / \mathrm{uterus}$ being reported (Yasuda et al., 1986). Assuming an average uterine wet weight of $500 \mathrm{mg}$, this is equivalent to $42 \cdot 6 \mathrm{ng} \mathrm{PAF} / \mathrm{g}$ wet weight of tissue or $81 \cdot 3 \mathrm{pmol} / \mathrm{g}$. Yasuda et al. (1986) also indicated that rabbit uteri contained PAF but in much smaller quantities (no data were given). In the studies presented here, PAF concentrations in oestrous rabbit uteri were $\sim 2 \mathrm{pmol} / \mathrm{g}$ wet weight, a value which is indeed considerably lower than that reported for the oestrous uterus of the rat. However, PAF in the hormonally stimulated rabbit uterus reached levels as high as $60 \mathrm{pmol} / \mathrm{g}$ wet weight of tissue, depending on the time elapsing before processing (see Table 1) and the day of pregnancy or pseudopregnancy. Concentrations of PAF in the rabbit uterus therefore approach levels that are similar to those reported by Yasuda et al. (1986) for the rat.

Pregnancy-associated production of PAF has also been implicated in mice and women. O'Neill et al. (1985) have shown that systemic maternal thrombocytopenia developed during early pregnancy in mice and women until about $48 \mathrm{~h}$ before the expected time of implantation. Platelet disappearance occurred only in the presence of the embryo since it was not seen in non-pregnant mice or women. O'Neill (1985a, b) has proposed that this pregnancy-associated systemic thrombocytopenia is the consequence of the release of a soluble factor from 8-16-cell embryos that is biologically very similar to platelet-activating factor. Partial characterization of this PAF-like activity was accomplished, including bioassay in splenectomized mice, use of inhibitors of various pathways of platelet activation and structural analysis using lipase digestion; PAF concentrations in zygotes were not measured. None the less, combined with the inhibition of implantation in mice and rats by PAF antagonists (Acker et al., 1987; Spinks \& O'Neill, 1987), these data suggest a significant role for PAF in the events of early pregnancy.

In contrast to the observations which suggest that a substance with PAF-like activity was produced by the preimplantation zygote (O'Neill, 1985a, b), the results of our studies show that detectable PAF, as measured directly in platelet secretion and aggregation assays after t.l.c. or h.p.l.c. isolation, was not found in Day-6 uterine fluid, or in Day-5 or -6 blastocysts that had been extracted immediately after flushing from the reproductive tract. In addition, PAF was not detected in Day- 5 blastocysts after $24 \mathrm{~h}$ culture in vitro or in the associated culture media. This discrepancy could be due to species differences (rabbits in these experiments), to measurement of different substances or to the stage of zygote development. Technical factors can also not be excluded. For instance, PAF is known to adhere to glass and plastic surfaces and the culture dishes were not siliconized nor was albumin added to the medium. These factors could therefore have influenced the failure to detect PAF in culture medium, but not in blastocysts themselves. However, the mouse and human zygotes were at a much earlier stage of development than the rabbit embryos which had already reached the expanded blastocyst stage, and this explanation seems the most likely. We concur that PAF appears to play an important role in early pregnancy. We suggest that PAF synthesized by the preimplantation uterus may play a more significant role in the regulation of implantation than does embryo-derived PAF. A uterine source of PAF seems critical since the changes in uterine PAF occur immediately before implantation, at a time when PAF production in the zygote has apparently ceased. Preliminary evidence from human endometrial cultures suggests that PAF is synthesized by stromal and not by epithelial cells (B. G. Casslén, R. Kumar, D. J. Hanahan \& M. J. K. Harper unpublished data), although epithelial cells have an obligate role in induction of decidualization of the stromal cells (Lejeune et al., 1981).

Peripheral oestrone concentrations remain low and unchanged throughout pregnancy in rabbits, as do those of oestradiol at least through Day 12 of pregnancy (Challis et al., 1973). Progesterone concentrations are not different between pregnant and pseudopregnant rabbits at least through Day 7 of pregnancy, but unlike the oestrogens, progesterone shows a sharp peak during the first $12 \mathrm{~h}$ after mating or hCG injection, then remains low until approximately $30 \mathrm{~h}$ and subsequently increases 
steadily up to Day 11 of pregnancy or pseudopregnancy (Spilman \& Wilks, 1976; Harrington \& Rothermel, 1977). Thus, the pattern of increase in uterine PAF concentrations closely mimics the increase in peripheral progesterone concentrations.

The involvement of the preimplantation blastocyst in the regulation of PAF biosynthesis is implied by the significantly different patterns of PAF concentrations in pregnant as compared to pseudopregnant animals at the time of implantation, the only difference between these groups of animals being the presence or absence of developing blastocysts (Fig. 2). In addition, the presence of the blastocyst must be related to the dramatic decline in PAF concentration on the day during which increased vascular permeability occurs in the stroma underlying the attaching blastocyst (Day 7 of pregnancy), since this decline was significantly greater at implantation sites than at interimplantation areas (Table 3). A number of possible explanations can be proposed to account for the disappearance of PAF from uterine tissue at the time of implantation: the presence of the blastocyst itself or a blastocyst-derived product through interaction with the luminal epithelium may directly or indirectly inhibit PAF synthesis in the underlying area; conversely, the embryo may stimulate PAF catabolism or utilization by the uterus. The correct explanation for the embryo-associated decrease in endometrial PAF remains to be determined.

Pharmacologically, PAF is one of the most potent inducers of vascular permeability (Humphrey et al., 1982) reported in the literature. Consequently, induction of PAF release by the presence of the blastocyst, together with the synergistic vasoactive effects of PAF (Humphrey et al., 1982) and prostaglandins (Jones et al., 1985), could play an important physiological role in the blastocystinduced vascular permeability in the stroma of the rabbit uterus commencing at 6 days of pregnancy and observable by Day 6.5 of pregnancy (Hoos \& Hoffman, 1980). Such an interpretation is strengthened by the low levels of PAF in the myometrium, minimal PAF changes in myometrium with increased progesterone concentrations, and lack of differences in myometrial PAF between pregnant and pseudopregnant animals (Table 4). This suggests that the observed endometrial changes are not artefactual.

It should be stressed that artefacts can be induced if care is not taken to process the tissue rapidly (Table 1). However, at least one potential source of PAF, intravascular leucocytes and platelets, can be eliminated as a major contributor of uterine PAF, since vascular perfusion before autopsy did not influence PAF recovery (Table 5).

In summary, it would appear that the dramatic changes seen in endometrial PAF concentrations at the site of blastocyst attachment are directly related to and important in the implantation process. This supposition is strengthened by the fact that injection of synthetic PAF into oestrous mice causes the appearance of early pregnancy factor in the sera (Orozco et al., 1986).

We thank C. Norris, E. Hemmick, W. Anderson, A. Moreno, K. Ostrom, K. Walton, C. Lear and P. Padilla for excellent technical assistance.

These studies were supported by NIH grants HD 14048, HL22555 and HL07350.

\section{References}

Acker, G., Hecquet, F., Etienne, A., Braquet, P.\& MenciaHuerta, J.M. (1987) Role des mediateurs lipidiques de l'inflammation dans l'ovoimplantation chez la ratte. In Immunologie de la Reproduction: relation MaternoFoetale, pp. 151-158. Ed. G. Chaouat. INSERM, Paris.

Angle, M.J., Jones, M.A., Pinckard, R.N., McManus, L.M. \& Harper, M.J.K. (1985) Platelet-activating factor (PAF) in the rabbit uterus during early pregnancy. Biol. Reprod. 32, Suppl. 1, 143, Abstr. 212.

Angle, M.J., McManus, L.M. \& Pinckard, R.N. (1986) Age-dependent differential development of leuko- tactic and vasoactive responsiveness to actue inflammatory mediators. Lab. Invest. 55, 616-621.

Bligh, E.G. \& Dyer, W.J. (1959) A rapid method of total lipid extraction and purification. Can. J. Biochem. Physiol. 37, 911-917.

Challis, J.R.G., Davies, I.J. \& Ryan, K.J. (1973) Concentrations of progesterone, estrone and estradiol-17 $\beta$ in the plasma of pregnant rabbits. Endocrinology 93, 971-976.

DeFeo, V.J. (1967) Decidualization. In Cellular Biology of the Uterus, pp. 191-290. Ed. R. M. Wynn. AppletonCentury-Crofts, New York. 
Dickmann, Z. \& Spilman, C.H. (1975) Prostaglandins in rabbit blastocysts. Science, N.Y. 190, 997-998.

Finn, C.A. \& Porter, D.G. (1975) The Uterus, pp. 93-95. Publishing Sciences Group, Inc, Acton, MA.

Folch, J., Lees, M. \& Sloane-Stanley, G.H. (1957) A simple method for the isolation and purification of total lipides from animal tissues. J. biol. Chem. 226, 497-509.

Harper, M.J.K., Norris, C.J. \& Rajkumar, K. (1983) Prostaglandin release by zygotes and endometria of pregnant rabbits. Biol. Reprod. 28, 350-362.

Harrington, F.E. \& Rothermel, J.D. (1977) Daily changes in peripheral plasma progesterone concentrations in pregnant and pseudopregnant rabbits. Life Sci. 20, 1333-1340.

Hoffiman, L.H., Strong, G.B., Davenport, G.R. \& Frolich, J.C. (1977) Deciduogenic effect of prostaglandins in the pseudopregnant rabbit. J. Reprod. Fert. 50, 231-237.

Hoos, P.C. \& Hoffman, L.H. (1980) Temporal aspects of rabbit uterine vascular and decidual responses to blastocyst stimulation. Biol. Reprod. 23, 453-459.

Hoos, P.C. \& Hoffman, L.H. (1983) Effect of histamine receptor antagonists and indomethacin on implantation in the rabbit. Biol. Reprod. 29, 833-840.

Humphrey, D.M., McManus, L.M., Satouchi, K., Hanahan, D.J. \& Pinckard, R.N. (1982) Vasoactive properties of acetyl glyceryl ether phosphorylcholine and analogues. Lab. Invest. 46, 422-427.

Humphrey, D.M., McManus, L.M., Hanahan, D.J. \& Pinckard, R.N. (1984) Morphologic basis of increased vascular permeability induced by acetyl glyceryl ether phosphorylcholine. Lab. Invest. 50, 16-25.

Jones, M.A., Norris, C.J. \& Harper, M.J.K. (1984) Effect of indomethacin in vivo on prostaglandin content of several rabbit tissues. Prostaglandins 28, 111-118.

Jones, M.A., Anderson, W., Turner, T.G. \& Harper, M.J.K. (1985) Storage in vivo of $\left[{ }^{3} \mathrm{H}\right]$-prostaglandins by rabbit blastocysts. Endocrinology 116, 993-997.

Jones, M.A., Cao, Z.-d., Anderson, W., Norris, C. \& Harper, M.J.K. (1986) Capillary permeability changes in the uteri of recipient rabbits after transfer of blastocysts from indomethacin-treated donors. $J$. Reprod. Fert. 78, 262-273.

Kennedy, T.G. (1977) Evidence for a role for prostaglandins in the initiation of blastocyst implantation in the rat. Biol. Reprod. 16, 286-29I.

Kennedy, T.G. (1979) Prostaglandins and increased endometrial vascular permeability resulting from the application of an artificial stimulus to the uterus of the rat sensitized for the decidual cell reaction. Biol. Reprod. 20, $560-566$.

Kennedy, T.G. (1985) Evidence for the involvement of prostaglandins throughout the decidual cell reaction in the rat. Biol. Reprod. 33, 140-146.

Kennedy, T.G. \& Lukash, L.A. (1982) Induction of decidualization in rats by the intrauterine infusion of prostaglandins. Biol. Reprod. 27, 253-260.

Kennedy, T.G. \& Zamecnik, J. (1978) The concentration of 6-oxo-PGF- $1_{a}$ is markedly elevated at the site of blastocyst implantation in the rat. Prostaglandins 16, 599-605.

Lejeune, B., Van Hoeck, J. \& Leroy, F. (1981) Transmitter role of the luminal uterine epithelium in the induction of decidualization in rats. J. Reprod. Fert.61, 235-240.
Majno, G. (1964) Mechanisms of abnormal vascular permeability in acute inflammation. In Injury, Inflammation and Immunity, pp. 58-93. Eds L. Thomas, J. W. Uhr \& L. Grant. Williams \& Wilkins, Baltimore.

MeManus, L.M. (1986) Pathobiology of plateletactivating factors. Pathol. Immunopathol. Res. 5, $104-117$.

Miwa, M., Hill, C., Kumar, R., Sugatani, J., Olson, M.S. \& Hanahan, D.J. (1987) Occurrence of an endogenous inibitor of platelet-activating factor in rat liver. J. Biol. Chem. 262, 527-530.

Mukherjee, A., Dey, S.K., Gupta, J.S., Ramadoss, C.S. \& Dickmann, Z. (1978) Regulatory enzymes of carbohydrate and energy metabolism in the rabbit blastocyst. J. Reprod. Fert. 53, 77-80.

O'Neill, C. (1985a) Examination of the causes of early pregnancy-associated thrombocytopenia in mice. $J$. Reprod. Fert. 73, 567-577.

O'Neill, C. (1985b) Partial characterization of the embryo-derived platelet-activating factor in mice. $J$. Reprod. Fert. 75, 375-380.

O'Neill, C., Pike, I.L., Porter, R.N., Gidley-Baird, A.A., Sinosich, M.J. \& Saunders, D.M. (1985) Maternal recognition of pregnancy prior to implantation: methods for monitoring embryonic viability in vitro and in vivo. Ann. N.Y. Acad. Sci. 442, 429-439.

Orozco, C., Perkins, T. \& Clarke, F.M. (1986) Plateletactivating factor induces the expression of early pregnancy factor activity in female mice. $J$. Reprod. Fert. $78,549-555$.

Pakrasi, P.L. \& Dey, S.K. (1982) Blastocyst is the source of prostaglandins in the implantation site in the rabbit. Prostaglandins 24, 73-77.

Phillips, C.A. \& Poyser, N.L. (1981) Studies on the involvement of prostaglandins in implantation in the rat. J. Reprod. Fert. 62, 73-81.

Pinckard, R.N., Farr, R.S. \& Hanahan, D.J. (1979) Physiochemical and functional identity of plateletactivating factor (PAF) released in vivo during IgE anaphylaxis with PAF released in vitro from IgE sensitized rabbit basophils. J. Immunol. 123, 1847-1857.

Pinckard, R.N., Jackson, E.M., Hoppens, C., Weintraub, S.T., Ludwig, J.C., McManus, L.M. \& Mott, G.E. (1984) Molecular heterogeneity of platelet activating factor produced by stimulated human polymorphonuclear leukocytes. Biochem. Biophys. Res. Commun. 122, 325-332.

Pschoyos, A. (1973) Endocrine control of egg implantation. In Handbook of Physiology, Section 7, Vol. II, Part 2, pp. 187-215. Eds R. O. Greep \& S. R. Geiger. Am. Physiol. Soc., Washington, DC.

Saksena, S.K., Lau, I.F. \& Chang, M.C. (1976) Relationship between oestrogen, prostaglandin $F_{2 a}$ and histamine in delayed implantation in the mouse. Acta endocr., Copenh. 81, 801-807.

Shelesnyak, M.C. (1957) Some experimental studies on the mechanism of ova implantation in the rat. Recent Prog. Horm. Res. 13, 269-317.

Sokal, R.R. \& Rohlf, F.J. (1969) Biometry. W. H. Freeman and Company, San Francisco.

Spilman, C.H. \& Wilks, J.W. (1976) Peripheral plasma progesterone during egg transport in the rabbit. Proc. Soc. exp. Biol. Med. 151, 726-729.

Spinks, N.R. \& O'Neill, C. (1987) Embryo-derived platelet-activating factor is essential for establish- 
ment of pregnancy in the mouse. Lancet 1 , 106-107.

Tobert, J.A. (1976) A study of the possible role of prostaglandins in decidualization using a non-surgical method for the instillation of fluids into the rat uterine lumen. J. Reprod. Fert. 47, 391-393.

Wedmore, C.V.\& Williams, T.J. (1981) Platelet activating factor (PAF) a secretory product of polymorphonuclear leucocytes increases vascular permeability in rabbit skin. Br. J. Pharmacol. 74, 916p-917p.

Yasuda, K., Satouchi, K. \& Saito, K. (1986) Plateletactivating factor in normal rat uterus. Biochem. Biophys. Res. Commun. 138, 1231-1236.

Received 22 October 1987 